\title{
Should the children of patients with hemochromatosis be screened for the disease?
}

\author{
Donald G. Macintosh, MD, John C. Bear, PhD, John Simpson, MD, FRCPC, \\ Terry A. Komusi, MD, FrCPC, William H. Marshall. MD, FRCP, James A. Barrowman, MD, FrCP
}

\begin{abstract}
Idiopathic hemochromatosis is an underdiagnosed treatable condition inherited in an autosomal recessive pattern. Since early treatment is of demonstrated value, screening of high risk groups of individuals in a valuable exercise in preventive medicine. Although examination of siblings is always recommended, the frequency of the hemochromatosis gene makes the screening of children of patients with hemochromatosis an important undertaking, as illustrated by the families described in this report. Can J Gastroenterol 1988;2(4):143-6
\end{abstract}

Key Words: Gene frequency, Genetic screening, Hemochromatosis, Recessive genes
V

ENESECTION EARLY IN THE COURSE of idiopathic primary hemochromatosis can prevent the iron overload which results in life threatening complications in this underdiagnosed disorder (1). Inheritance of hemochromatosis is autosomal recessive; it has been estimated that approximately $10 \%$ of the population in North America and Europe are heterozygous for the hemochromatosis gene, formally designated HFE (2,3). These two observations have important implications, in terms of screening relatives of patients to determine whether they are homozygous for HFE and, therefore, have the hemochromatosis genotype.
Screening itself is inexpensive and simple; measurement of transferrin saturation will accurately identify at least $90 \%$ of persons homozygous for HFE (4-6). The autosomal recessive inheritance of the condition implies that siblings of patients are at $25 \%$ risk of being homozygotes themselves and should be screened. However, because of the high frequency of the HFE gene in the general population, offspring of affected individuals are also at a considerably elevated risk of homozygosity and clinical disease. Two Newfoundland families which illustrate the value of screening offspring, as well as siblings, of hemochromatosis patients are presented.
Faculty of Medicine, Memorial University of Newfoundland; and St Clares Mercy Hospital. Stlohn's, Newfoundland

Correspondence and reprints: Dr J.A. Barrowman, Faculty of Medicine, Memorial University of Newfoundland, St John's, Newfoundland A IB 3V6. Telephone (709) $737-6546$

Received for publication July 21. 1988. Accepted August 22, 1988

\section{PATIENTS AND METHODS}

Diagnosis: A provisional diagnosis of hemochromatosis was made with a transferrin saturation (serum iron/total iron binding capacity $\times 100$ ) greater than $55 \%$ and a serum ferritin level greater than the 90 th percentile (6). Percutaneous liver biopsies were performed on these individuals and histological demonstration of parenchymal iron deposition was taken as confirming the diagnosis of hemochromatosis. HLA typing of affected and unaffected family members allowed the cotransmission of the HFE gene and particular HLA haplotypes to be followed in families $(3,7)$.

Patients: The index case of family 1 (Figure 1) was a man of 55 years who presented with dark skin pigmentation and had a history of arthritis involving hands and shoulders; he had no children. In his sibship of five, one sister had hemochromatosis; she was asymptomatic. Of her six children, three were found to be affected. Of note, two of her affected sons were attending a rheumatology clinic on account of arthritis but had not previously been diagnosed as having hemochromatosis.

The index case in family 2 (Figure 2) presented at age 73 with abnormal skin pigmentation. He had one son, unaf- 


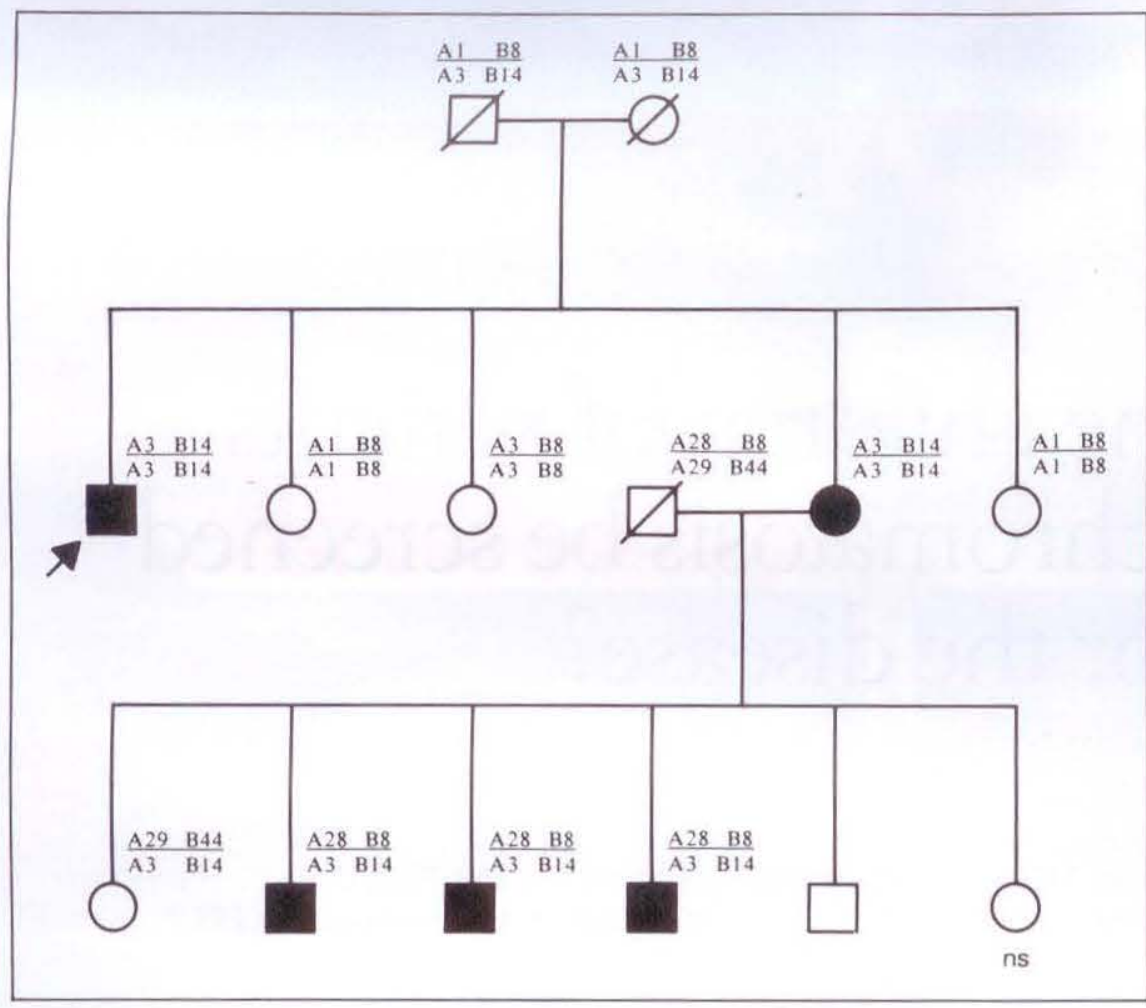

Figure 1) Family 1. $\square$ Male; $\bigcirc$ Female; Not studied

fected. In his sibship of eight, one brother was affected and of this brother's offspring, seven were tested and three were found to have hemochromatosis.

In both families, liver biopsies of those individuals provisionally diagnosed using iron metabolism studies revealed moderate to heavy parenchymal iron deposition in every case. In no case was any alteration of liver architecture found, nor was any excess fibrous tissue deposition found.

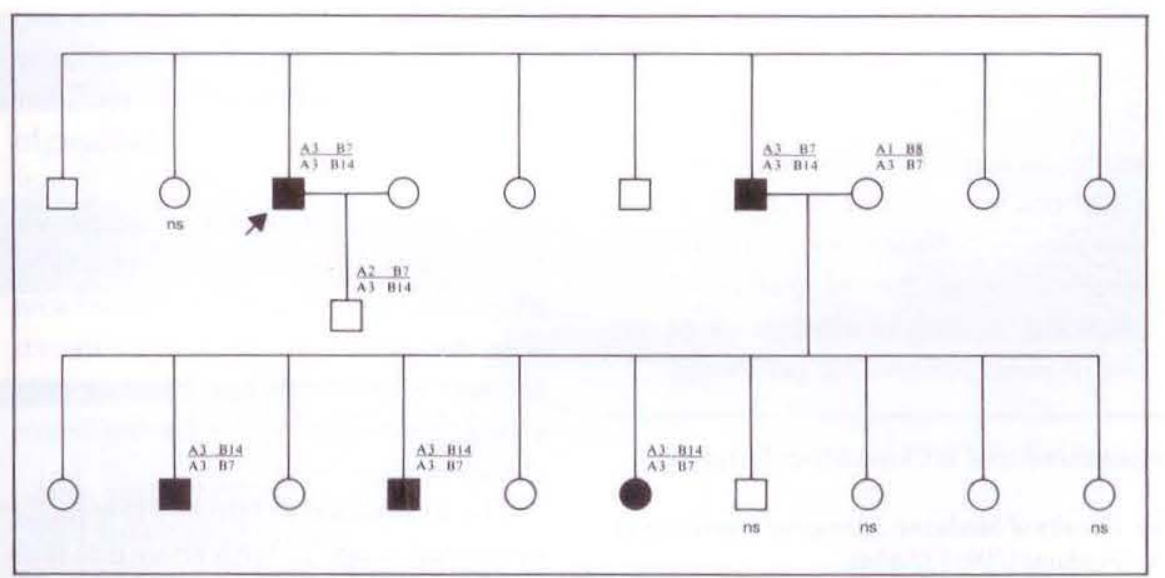

Figure 2) Family 2. See Figure 1 for key to symbols other clinical consequences of iron overload, and every expectation of a normal life span (1).

\section{DISCUSSION}

Estimates of the frequency of HFE range around 0.05 , making it the most common deleterious autosomal recessive gene as yet described in the white populations of northern Europe, North America and Australia (8). Consequently, about $10 \%$ of persons are expected to be heterozygous for the gene and two to three persons per 1000 are homozygotes and at risk of clinical hemochromatosis by late middle age if not before.

Because $10 \%$ of the spouses of hemochromatosis patients will be HFE heterozygotes, simply by chance, it is not surprising that families, such as those reported here, are observed in which hemochromatosis occurs in the offspring of patients. In a mating between an affected (homozygous) and a carrier (heterozygous) individual, all offspring will necessarily receive the HFE gene from the affected (homozygous) parent and each has a $50 \%$ chance of receiving the HFE gene from the unaffected, heterozygous parent. On average, one-half of the offspring of such matings are expected to be homozygous for HFE, likely to develop clinical hemochromatosis eventually. This is illustrated by the families reported here: three of six children in family 1 and three of seven children in family 2 are affected.

As indicated, $10 \%$ of matings of patients are expected to be of this type; families showing vertical transmission of hemochromatosis are probably not observed more frequently simply because the onset of hemochromatosis is relatively late in life. Such pseudodominant transmission of the clinical disease confused early attempts to elucidate its mode of inheritance. Clear appreciation of recessive inheritance required the discovery that the HFE locus is closely linked to the HLA A locus on chromosome 6 and the use of measurements of iron load to identify family members with presymptomatic disease (9-11). Families such as those reported here would have escaped notice because some family members with hemochromatosis are asymptomatic and because affected younger 
members showed minimal clinical signs of hemochromatosis. These two families highlight the significance of arthropathy as an early manifestation of this disease and as a useful clue in differential diagnosis $(1,12)$.

If approximately $10 \%$ of spouses of hemochromatosis patients are expected to be HFE heterozygotes and one-half of the offpsring of such matings are expected to be homozygous, overall, about $5 \%$ of offspring of all patients taken together will be HFE homozygotes. Clearly, there is a strong case for investigating, screening and following-up patients' offspring, as well as patients' siblings.

Thought should be given to the most economical method of investigating persons at risk. Serum transferrin saturation is an efficient screening test and will identify persons at risk of iron overload. Transferrin saturation screening of patients families should, therefore, identify most relatives who are also HFE homozygotes. If transferrin saturation is elevated, a repeat fasting test should be done; if this is elevated, serum ferritin concentration should be measured; if ferritin is elevated, liver biopsy studies are indicated (12).

HLA studies will almost always identify those relatives homozygous for HFE, and may be of use in interpreting borderline results of iron loading tests or results complicated by other considerations. For instance, for a young female relative of a patient, HLA studies of the family could show whether a marginally elevated transferrin saturation was in fact associated with HFE homozygosity. HLA studies might also prove informative in disentangling the effects of the HFE gene and alcohol abuse in families. HLA studies are, however, considerably more expensive than measurements of iron loading and because transferrin (and, if indicated, ferritin) studies should be done on all relatives of patients, HLA studies do not seem strictly necessary in most families. In family 2, for instance, the authors chose not to obtain HLA genotypes for a number of relatives whose transferrin saturations did not indicate a provisional diagnosis of hemochromatosis.

In evaluating relatives of patients and following the transmission of HFE genes in families, it should be remembered that occasional HFE heterozygotes may suffer from iron overload, either by virtue of metabolic abnormality or the coexistence of heterozygote status and environmental factors such as alcohol abuse.

The authors believe family screening with the aim of presymptomatic identification and treatment of persons homozygous for the HFE gene is a fundamental aspect of appropriate clinical management of hemochromatosis. Edwards and colleagues (12) have demonstrated marked variability of liver iron stores in hemochromatosis patients of similar ages and at present it does not seem possible to predict the progression of the disease in homozygotes. It seems reasonable to treat all homozygotes prophylactically once evidence of iron overload is found; venesection is harmless, effective treatment which can be adjusted to achieve a quantifiable clinical response (13). Niederau and co-workers (1) demonstrated a significant reduction of life expectancy in patients whose hemochromatosis had resulted in cirrhosis or diabetes and that patients treated prior to the onset of cirrhosis had an expectation of survival indentical to that of the general population. Of particular note, hepatocellular carcinoma, a recognized complication of hemochromatosis, has never been reported in noncirrhotic patients with hemochromatosis (1).

The pattern of association of the HFE gene with certain HLA haplotypes suggests that a small number of mutations, or perhaps a single mutation event, is responsible for this gene (14). This raises the possibility that tests using oligonucleotide DNA probes could be developed, which would allow homozygotes and heterozygotes to be identified accurately, simply and cheaply. Developing such probes would not be easy; this

\section{Les enfants des patients atteints d'hémochromatose : Devraient-ils être soumis à un examen de dépistage?}

L'hémochromatose est une condition curable sous diagnostiquée qui se transmet sur le mode autosomique récessif. L'importance de traiter le sujet atteint le plus tôt possible étant cer taine, le dépistage des groupes à haut risque est une mesure de médecine préventive impérative. Bien que l'examen des frères et soeurs soit toujours recommandé, la fréquence du gène porteur de l'hémochromose accentue la nécessité de dépister les enfants des patients atteints d'hémochromatose, ainsi que le démontre les familles dont fait état ce rapport. 


\section{REFERENCES}

1. Niederau C, Fischer R, Sonnenberg A, Stremmel W, Trampisch HJ, Strohmeyer G. Survival and causes of death in cirrhotic and in noncirrhotic patients with primary hemochromatosis. $\mathrm{N}$ Engl J Med 1985;313:1256-62.

2. McKusick VA. Mendelian Inheritance in Man. Baltimore: Johns Hopkins, 1986;1022-5.

3. Simon M, Brissot P. Review: The genetics of haemochromatosis. J Hepat 1988;6:116-24.

4. Dadone MM, Kushner JP, Edwards CQ Bishop DT, Skolnick MH. Hereditary hemochromatosis: Analysis of laboratory expression of the disease by genotype in 18 pedigrees. Am J Clin Pathol 1982:78:196-207.

5. Borwein ST, Ghent CN, Flanagan PR, Chamberlain MJ, Valberg LS. Genetic and phenotypic expression of hemochromatosis in Canadians. Clin
Invest Med 1983;6:171-9.

6. Borwein S, Ghent CN, Valberg LS. Diagnostic efficacy of screening tests for hereditary hemochromatosis. Can Med Assoc J 1984;131:895-901.

7. Bassett ML, Doran TJ, Halliday JW, Bashir HV, Powell LW. Idiopathic hemochromatosis: Demonstration of homozygous-heterozygous mating by HLA typing of families. Hum Genet 1982;60:352-6.

8. Rotter J1, Diamond JM. What maintains the frequencies of human genetic diseases? Nature 1987:329:289-90.

9. Simon M, Bourel M, Genetet B, Fauchet R. Idiopathic hemochromatosis:

Demonstration of recessive transmission and early detection by family HLA typing. N Engl J Med 1977; 297:1017-21.

10. Car twright GE, Edwards CQ, Kravitz K, et al. Hereditary hemochromatosis: Phenotypic expression of the disease. N Engl J Med 1979;301:175-9.
11. Kravitz K, Skolnick M, Cannings C, et al. Genetic linkage between hereditar hemochromatosis and HLA. Am J Hum Genet 1979:31:601-19.

12. Edwards CQ, Cartwright GE, Skolnick $\mathrm{MH}, \mathrm{Amos}$ DB. Homozygosity for hemochromatosis: Clinical manifestations. Ann Intern Med 1980;93:519-25

13. Edwards CQ, Criffen LM, Goldgan D, Drummond C, Skolnick MH, Kushner JP. Prevalence of hemochromatosis among 11,065 presumably healthy blood donors. N Engl ] Med 1988;318:1355-62

14. Simon M, Le Mignon L, Fauchet R, et al. A study of 609 HLA haplotypes marking for the hemochromatosis gene (1) Mapping of the gene near the HLA-A locus and characters required to define a heterozygous population and (2) Hypothesis concerning the underlying cause of hemochromatosis-HLA associa tion. Am J Hum Genet 1987;41:89-105. 


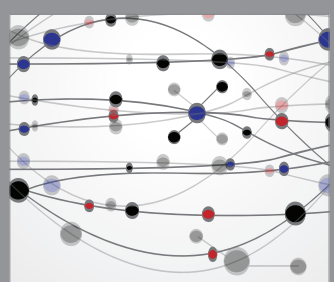

The Scientific World Journal
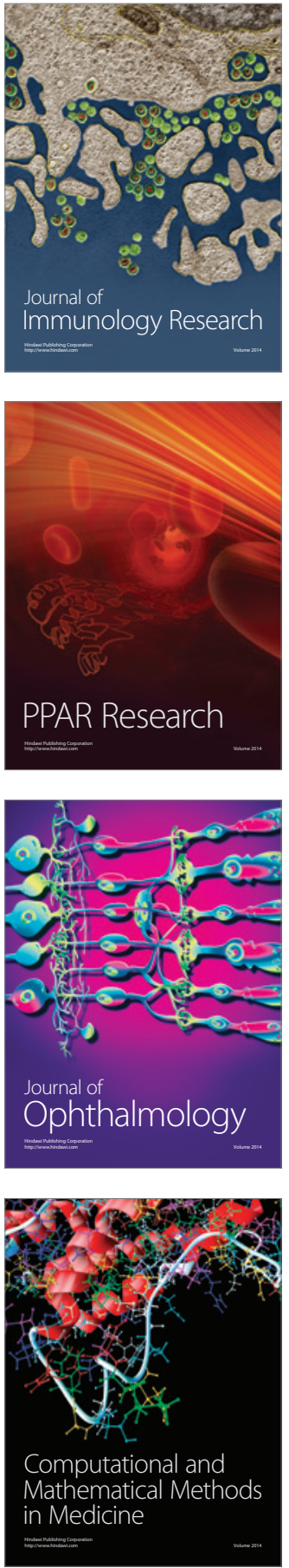

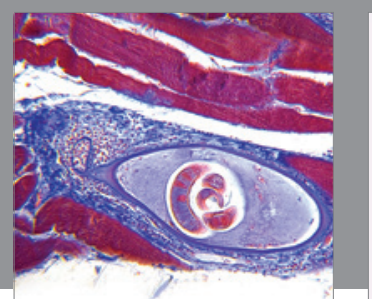

Gastroenterology Research and Practice

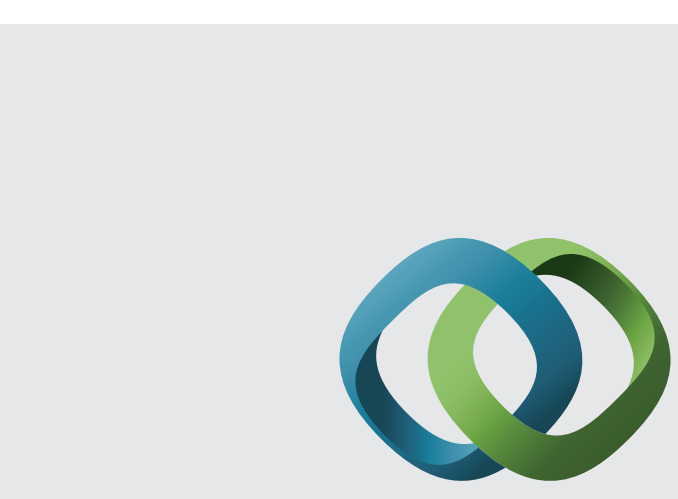

\section{Hindawi}

Submit your manuscripts at

http://www.hindawi.com
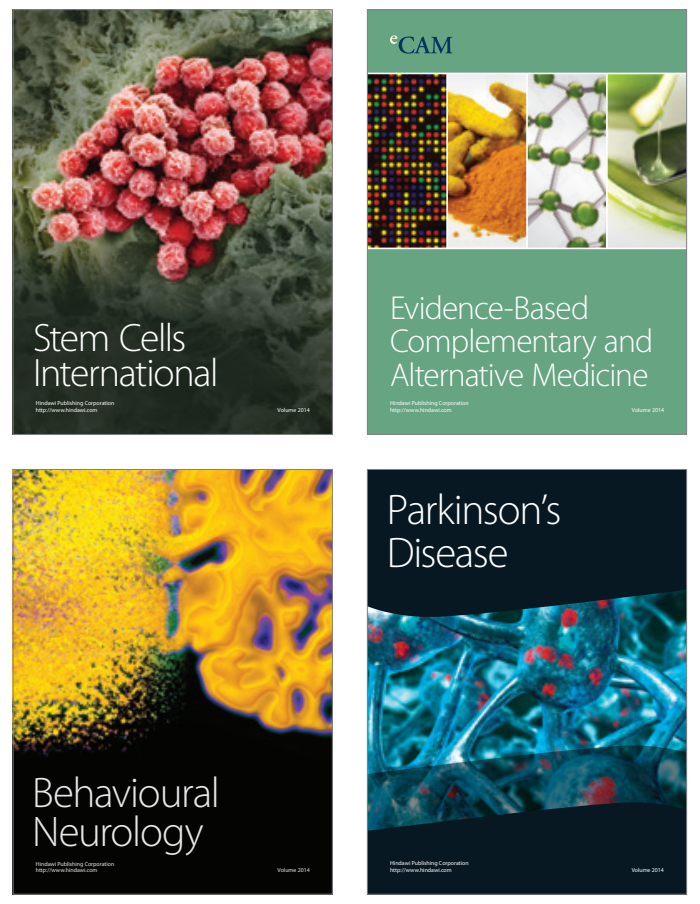
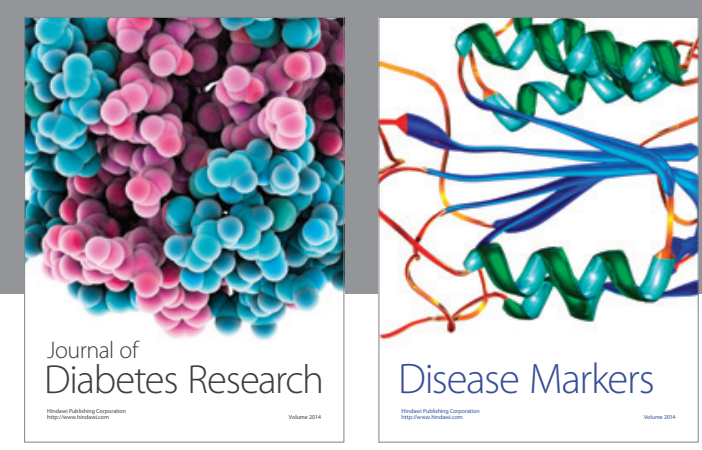

Disease Markers
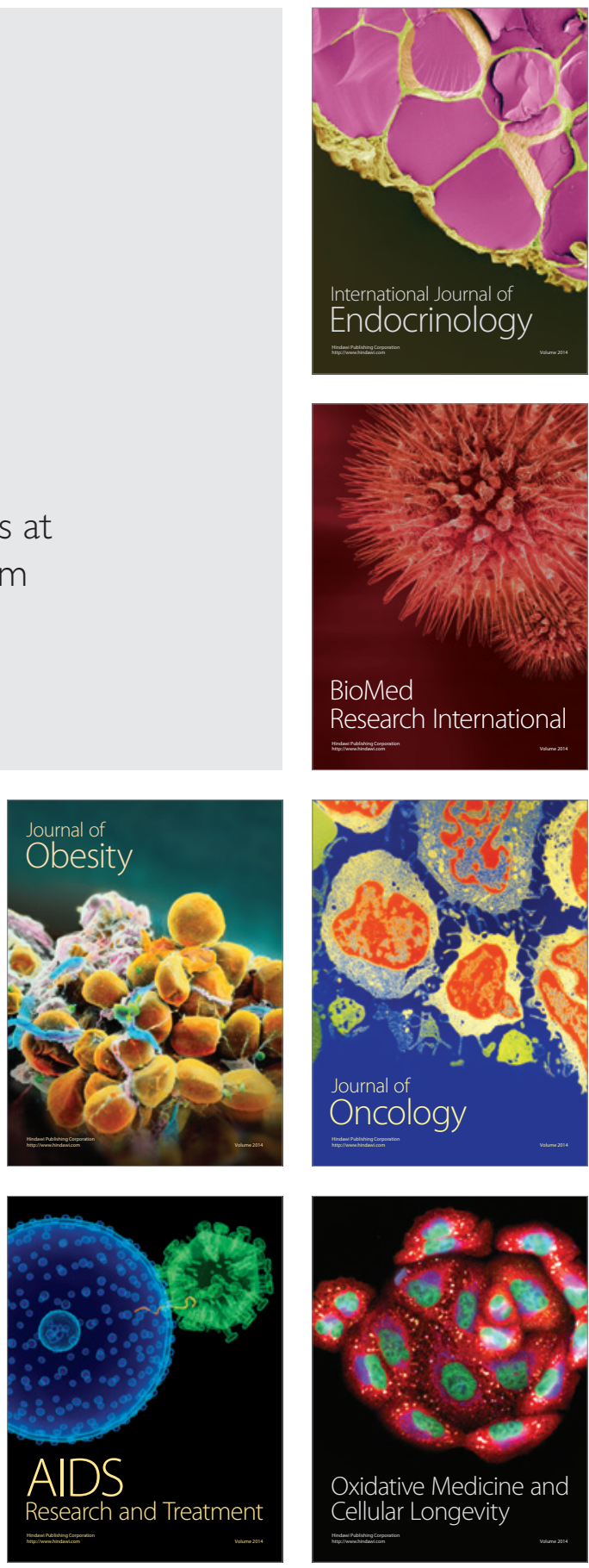